\title{
The Heat Transfer Characteristics in Stepped Hole of Traditional Metal Materials Induced by Stepped Film Holes
}

\author{
LIN LIBING*, ZHANG BO, LI JIQUAN, ZHANG NARU
}

Jiangsu Province Key Laboratory of Aerospace Power System, College of Energy and Power Engineering, Nanjing University of Aeronautics and Astronautics, Nanjing 210016, China

\begin{abstract}
With the increase of temperature requirement, the application of metal matrix materials is gradually reduced due to its poor temperature resistance. In order to improve the application of traditional metal based materials, new cooling technology must be developed to meet the application of metal based materials. In this paper, the cooling flow field of cylindrical hole and two kinds of stepped film holes based on metal materials is simulated by large eddy method(LES), the development of vortex structure and flow characteristics in the mixing area of coolant flow and mainstream are analyzed and studied. The distribution is strongly effected by stronger thermal convection compared with the new temperature resistant material. The results show that four kinds of vortices form downstream the film hole, namely, horseshoes vortex, shear layer vortex, hairpin vortex and the counter rotate vortex pair (CVP). The CVRP formed on the stepped plane which strongly influences the flow and heat transfer of downstream, which is more evident in metal based materials, especially resulted by its isotropic features. Compared with the cylindrical film hole, the structure of step plane efficiently decreases the coolant flow velocity which results in a decrease of the CVP intensity so that the cooling film is adherent to the wall. The thermal conductivity of metal base material is strong, which has a great influence on the temperature distribution inside the wall. Velocity pulsation tightly influenced by CVP, in where the CVP intensity is strong, velocity pulsation is also strong so that the coolant flow strongly mixes with the mainstream. The flow velocity and velocity pulsation decrease with the increasing of the area ratio of stepped hole. The influence of geometric parameters on the heat transfer performance is mainly due to the high heat transfer performance of the metal matrix material.
\end{abstract}

Keywords: film cooling, LES; vortex structure, cooling effect

\section{Introduction}

Film cooling is a kind of cooling technology widely used in gas turbine combustion chamber, turbine blade and other high temperature components. Most of the numerical simulation investigations in industry are carried out by RANS turbulence model. Since the gas flowing out of the film hole will form a complex vortex structure during mixing with the mainstream, it is of great significance to reveal the vortex developing and formation mechanism for the further understanding of film cooling mechanism and the optimization of the film cooling design [1-10].

The flow essence of gas film orifice jet is JICF (Jet In Cross Flow). Kamotani and Greber 1 may be the earliest to systematically describe the downstream structure of jet. Their research showed that a counter vortex pair is observed in the jet wake and can affect the downstream flow field which propagates far away. Kruse 2 studied the topological structure of the downstream flow of the isolated inclined hole, and described the interaction process between holes in the case of a single row

*email: mailto:zhang.bo123@yahoo.com 
hole jet. Fric and Roshko 11 used the flow field display technique to measure the vortex structure downstream of the film hole. It is pointed out that the vortex system near the film hole is mainly composed of four kinds of vortices, namely, horseshoe vortex, shear vortex, wake vortex and CVP. Kelso et al. 13 measured the generation and evolution of spin disaster in jet wake by laser scanner. The measurement results showed that the pulsation of wake vortex is widely distributed on the length scale. Andreopoulos 14 studied the vortex structure and mixing process in vertical jet wake by spectral analysis. Sarkar 15 studied the behavior of wake and evaluated film-cooling effect and discussed the evolution of vortex structures by LES. Tyagi and Acharya 16 performed LES for a row of inclined round film hole. They reported that the hairpin-vortex dominates the flow field and the leg of hairpin structure is the origination of CVP while the head is associated with roller vortex. El-Gabry et al. 17 measured the wake of inclined film hole by hot-wire anemometer. They pointed out that flow direction and lateral pulsation dominate the wake. Bidan et al. [18, 19] investigated the vortices structure both under unforced and forced conditions numerically. Kalghatgi and Acharya 20 performed LES for a single round inclined cooling jet of $35 \mathrm{deg}$ and discussed the evolution of Kelvin-Helmholtz (K-H) vortex, hairpin vortex and CVP structures. Sakai et al. 21 concluded that the hanging vortex and hairpin vortex are the origins of CVP at low density ratio while the hanging vortex and the shear jet vortex are the source of CVP at high density ratio. Wang chunhua et al. [22] investigated the flow-filed from converging-slot and fan shaped hole numerically adopting LES method. Bo Zhang et al. [23] experimentally investigated the influence of lamilloy cooling structure on flow and heat transfer characteristics [24-31].

A new scheme was developed simplified on the basic of the lamilloy structure by merging the two imp/film plates into one, whose excellent heat transfer characteristics was reported in [16].Since the scheme(stepped hole structure) has achieved good cooling effect, its internal mechanism has attracted many researchers' interest. In this paper, the cooling flow field of stepped film holes with different aperture ratio are studied by using the large eddy simulation method, and the jet trace, large-scale coherent structures and velocity pulsation characteristics of the three models are analyzed

\section{Mathematical Formulations and Numerical Modeling}

\subsection{Governing Equation and Subgrid-Scale Stress Model}

In the large eddy simulation, the N-S equations are filtered by establishing the filter function, and the motion behavior of the large scale vortex is solved explicitly, while the small vortex is modeled by the sub-grid model. In this paper, the dynamic Smagorinsky model is used to average the instantaneous variables of each flow field on the grid scale. The instantaneous variables $\phi(x, t)$ are divided into large scale $\phi^{\prime}(\mathrm{x}, \mathrm{t})$ and small scale $\bar{\phi}(\mathrm{x}, \mathrm{t})$ by filtering, and the $\bar{\phi}(\mathrm{x}, \mathrm{t})$ are obtained by following weighted integral.

$$
\bar{\phi}(x, t)=\int_{\Omega} G\left(x-x^{\prime}, \Delta\right) \phi\left(x^{\prime}, t\right) d x^{\prime} \#
$$

where $\mathrm{G}\left(\mathrm{x}-\mathrm{x}^{\prime}, \Delta\right)$ is the filter function, $\Omega$ is the computational region, and $\Delta$ is filter width, which is related to the grid resolution. When the filtering function represented by formula (1) is used to deal with the N-S equation of incompressible flow in instantaneous state, the continuity and momentum equations can be presented as follows: 


$$
\begin{gathered}
\frac{\partial \bar{u}_{j}}{\partial \bar{x}_{j}}=0 \# \\
\frac{\partial \bar{u}_{l}}{\partial t}+\frac{\partial\left(\overline{u_{j} u_{l}}\right)}{\partial \bar{x}_{j}}=\bar{f}_{l}-\frac{1}{\rho} \frac{\partial \bar{p}}{\partial x_{i}}+\frac{1}{\rho} \frac{\partial\left(\overline{\tau_{j l}}+\tau_{j i, S G S}\right)}{\partial x_{j}} \#
\end{gathered}
$$

where $\tau_{\mathrm{ji}, \mathrm{SGS}}=-\rho\left(\overline{\mathrm{u}}_{\mathrm{i}} \mathrm{u}_{\mathrm{j}}-\overline{\mathrm{u}}_{\mathrm{l}} \overline{\mathrm{u}}_{\mathrm{j}}\right)$ is the subgrid-scale stress, and the idea of subgrid-scale stress models is based on eddy viscosity assumption in RANS, and its expression is as follows:

$$
\tau_{j i, S G S}-\frac{1}{3} \tau_{k k, S G S} \delta_{i j}=2 \mu_{S G S} \overline{S_{l J}} \#
$$

where $\mu_{\mathrm{SGS}}$ is the eddy viscosity coefficient, which can be obtained from the sub-grid model, and $\mu_{\mathrm{SGS}}=\left(\mathrm{C}_{\mathrm{S}} \Delta\right)^{2}|\overline{\mathrm{S}}|$, thus

$$
\tau_{j i, S G S}-\frac{1}{3} \tau_{k k, S G S} \delta_{i j}=2 \rho\left(C_{S} \Delta\right)^{2}|\bar{S}| \overline{S_{l \jmath}} \#
$$

where $\mathrm{C}_{\mathrm{s}}$ is the Smagorinsky constant, which depends on the motion state and properties of the fluid. The formula (5) is the stress term obtained after considering the influence of small eddy, that is, subgrid-scale stress.

\subsection{Physical Model}

Based on the cold flow channel and heat flow channel of an engine combustion chamber, the height of cold flow channel is $21 \mathrm{~mm}$ and the height of heat flow channel is $42 \mathrm{~mm}$. Due to the periodicity of film hole arrangement, four film holes are selected in circumferential direction as the research object, the period length of perforate plate is $10.9 \mathrm{~mm}$, the distance between film hole and inlet is $20 \mathrm{~mm}$, and the distance from outlet is $55 \mathrm{~mm}$ (as shown in Figure 1).

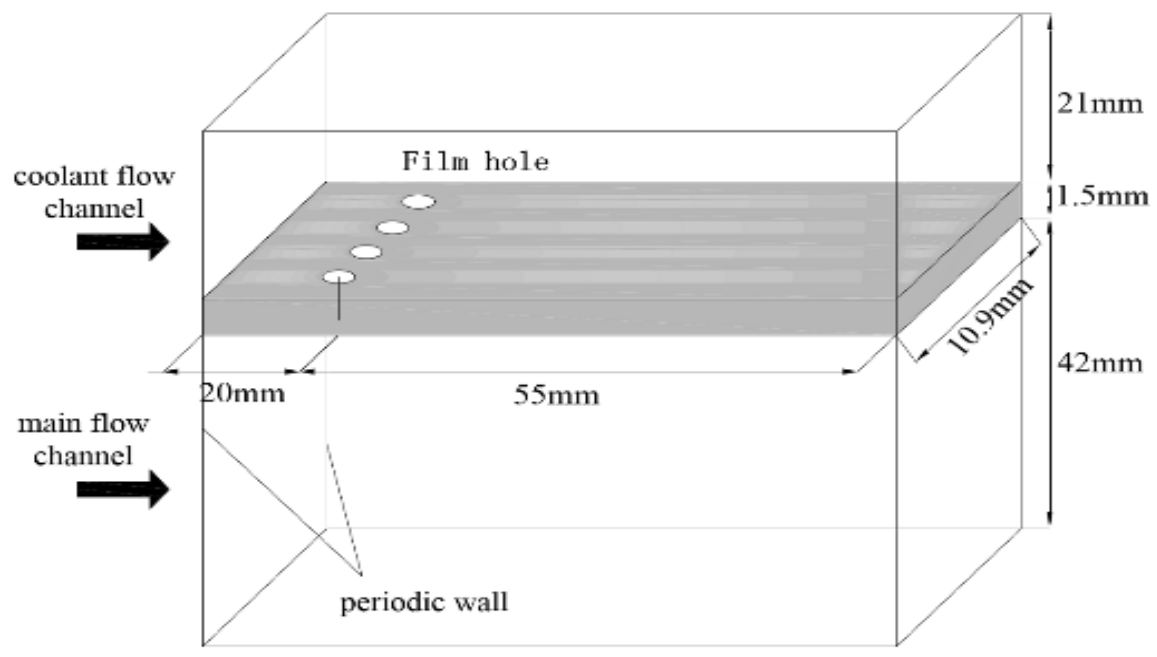

Figure 1. Sketch of computational domain

The structure of film hole details is shown in 

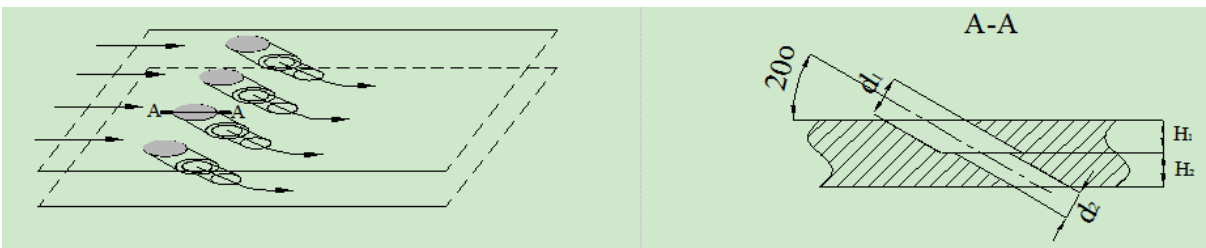

Figure 2 and Figure 3. The inclination angle of gas film hole of the three models is $20^{\circ}$, and the stepped hole is composed of two parts, where D1 represents the bigger area of stepped hole, D2 represents the smaller area of stepped hole, $\mathrm{H}_{1}$ is the height of the bigger stepped hole, and $\mathrm{H}_{2}$ is the height of the smaller stepped hole, and its parameters are shown in table 1 below. And the details of the stepped hole are shown in Figure 3.

Table 1. Geometry parameter of film hole

\begin{tabular}{cccc}
\hline Model & $\mathrm{D} 1(\mathrm{~mm})$ & $\mathrm{D} 2(\mathrm{~mm})$ & $\mathrm{H}_{1} / \mathrm{H}_{2}$ \\
\hline Model1 & 0.7 & - & - \\
Model2 & 0.84 & 0.64 & 1 \\
Model3 & 1.22 & 0.61 & 1 \\
\hline
\end{tabular}
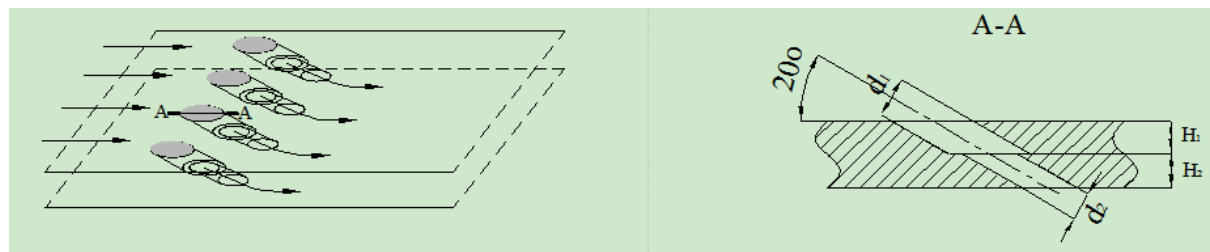

Figure 2. The structure of stepped holes
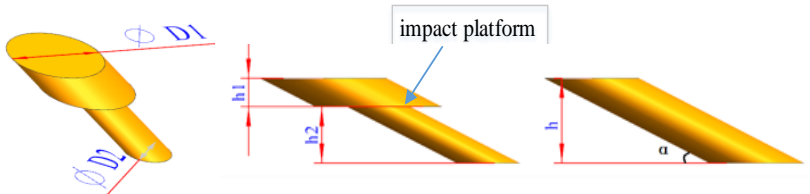

Figure 3. The details of stepped film holes

\subsection{Grid Generation and Boundary Conditions}

According to the physical model of this paper, the accuracy and resources of the calculation are considered comprehensively, and dense grids is applied adhere to the wall of the hot side to meet the requirements of high gradient of temperature and velocity near wall. In this paper, the structured grids are used(seen in Figure 4), and the range of $y^{+}$is $0.5 \sim 2$. After the verification of grid independence, the total amount of grid is about 3.1 million. In this paper, the boundary conditions of the model are set as follows: the velocity of the given heat flow channel is $50 \mathrm{~m} / \mathrm{s}$, and the velocity of the cold flow channel is $40 \mathrm{~m} / \mathrm{s}$. 


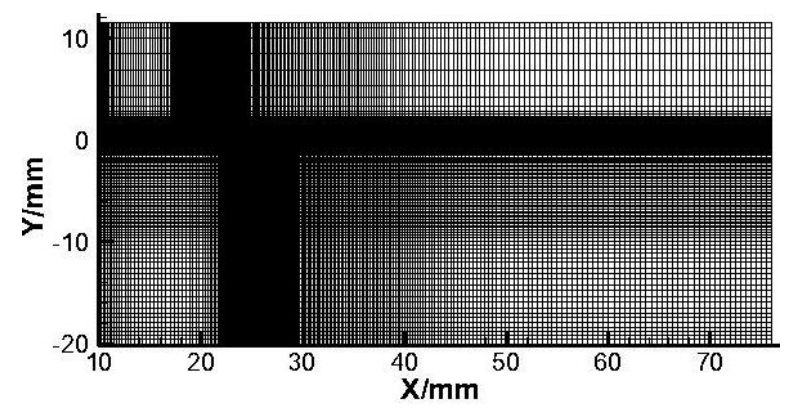

Figure 4. Sketch of grid in periodic plane

\subsection{Discrete Format and Algorithm}

The software Ansys-Fluent is used to conduct the simulations in this paper. The second-order upwind difference scheme is adopted for each equation, and the convergence judgment standard of the numerical solution is the relative residual of each physical quantity is less than $10^{-7}$. The minimum grid scale $\Delta x \min =0.005 \mathrm{~mm}$, the maximum flow speed of the fluid Umax $=50 \mathrm{~m} / \mathrm{s}$, the minimum time $\Delta \mathrm{t}=10^{-7} \mathrm{~s}$, in order to observe the generation of vortex structure, the time step is set to $10^{-7} \mathrm{~s}$ first, and then the time step size is adjusted to $10^{-6} \mathrm{~s}$, so as to improve the calculation iteration speed, the iterative calculation is 50,000 steps in total. And the calculation flow is ensured to flow through the whole computational domain.

\subsection{Vortex Structure Analysis Method}

In the paper, the definition of vortex core are proposed based on the $\mathrm{Q}$ criterion of velocity tensor $\mathrm{u}$, the $\mathrm{Q}$ function is defined as

$$
Q=\frac{1}{2}\left(\Omega_{i j} \Omega_{i j}-\mathrm{S}_{i j} \mathrm{~S}_{i j}\right) \#
$$

Where $\Omega_{i j}$ and $S_{i j}$ are defined as

$$
\begin{aligned}
& \Omega_{i j}=\frac{1}{2}\left(\frac{\partial u_{i}}{\partial x_{j}}-\frac{\partial u_{j}}{\partial x_{i}}\right) \# \\
& S_{i j}=\frac{1}{2}\left(\frac{\partial u_{i}}{\partial x_{j}}+\frac{\partial u_{j}}{\partial x_{i}}\right) \#
\end{aligned}
$$

The vortex structure is dominant in this region. Jeong and Hussai also pointed out that the local pressure should be minimum when the $\mathrm{Q}$ criterion is used to indicate the existence of the vortex core.

\section{Numerical Simulation results}

\subsection{Evolution Process of Coolant Outflow and Cooling Efficiency Diagram}

The three models have similar vortex structure of the formation process, while the vortex structure evolution process of Model 2 is selected to describe in this section, which is shown in Figure . The vortex structure of the film hole cooling flow field is identified by $\mathrm{Q}$ criterion, and vortex structure is colored by velocity. 


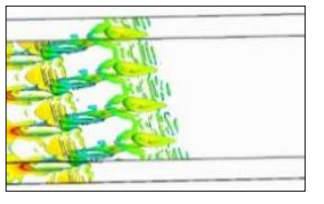

(a) The initial step of film hole outflow
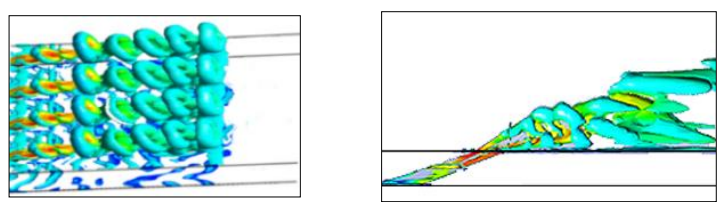

(b) Full development step

Figure 5. Evolution of film hole outflow (taking Model2 as example)

As shown in Figure (a), the mainstream forms a horseshoe vortex surrounding around the base of coolant jet because the flow is blocked by coolant flow upstream of the jet, the horseshoe vortex forms a smaller wake vortex on both sides of the jet in the downstream flow process, when the coolant flow ejects out of the film hole at a faster velocity, a shear vortex will be formed in the interface with the mainstream. However, the shear vortex was too small to be captured in this simulation. At the same time, the coolant jet incessantly entrains the mainstream, forms a hairpin vortex structure, and rises continuously in the process of downstream flow. Due to the decrease of local pressure caused by the mainstream below the jet, a part of gas of the hairpin vortex replenished downward, the mainstream is absorbed again and the second hairpin vortex continues to rise. Therefore, in the process of downstream flow, the coolant flow continuously entrains the main flow and mixes it to form hairpin vortexes [20, 32-40] .

When the flow is fully developed, as shown in Figure (b), the coolant flow strongly mixed with the mainstream to form a CVP, which has strong energy and is a large scale vortex in the film cooling flow field. These vortex structures make the coolant flow entrain the mainstream and greatly enhance the heat transfer between the plate wall and the coolant flow. Besides, these large scale vortexes maintain their structure from near field to far field so that they influence the flow and heat transfer of the downstream flow field.

\subsection{Flow Field and Thermal Side Cooling Efficiency}

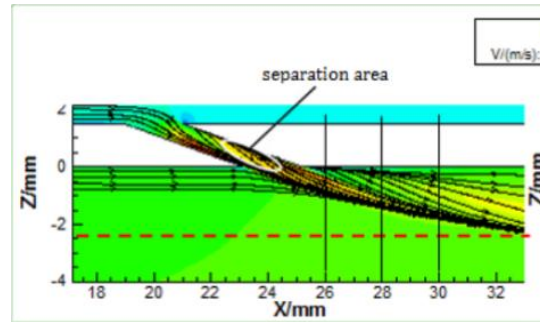

(a) Model 1

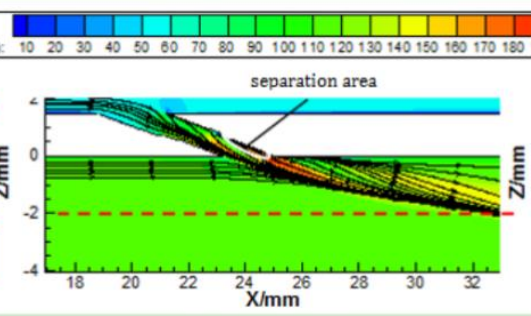

(b) Model 2

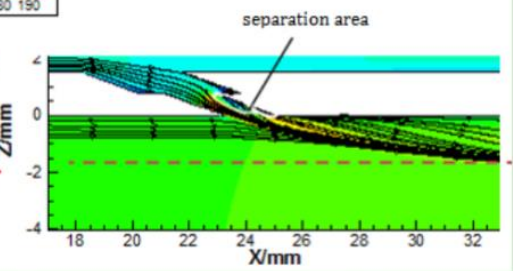

(c) Model 3

Figure presents velocity field and streamline through hole central plane of three models. Compared with Model 1, Model 2 and Model 3 have an impact on the stepped plane which reduces the jet velocity, suppress the penetration of coolant jet to the mainstream, and the cooling film adheres to the wall better (shown in the red dotted line). The separation area of cooling air flow in the film hole decreases in turn, as shown in the white circle in the figure, which results from the equal cross section of film hole in Model 1. And the velocity increases due to the decrease of the flow area after the cooling gas flows into the film hole, which leads to a larger separation area. Since the cooling gas velocity of Model 2 and Model 3 decreases on the stepped plane, the separation area in the small hole is smaller than that in Model 1. In addition, because the impact platform of Model 3 is larger than that of Model 2, the velocity decreases more on the stepped plane, so the separation zone inside 
the hole is smaller and the cooling film is closer to the wall [20-22, 41-49].

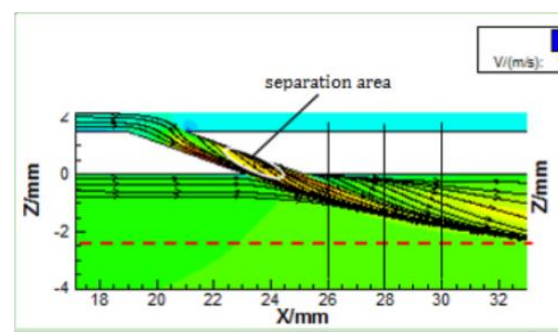

(a) Model 1

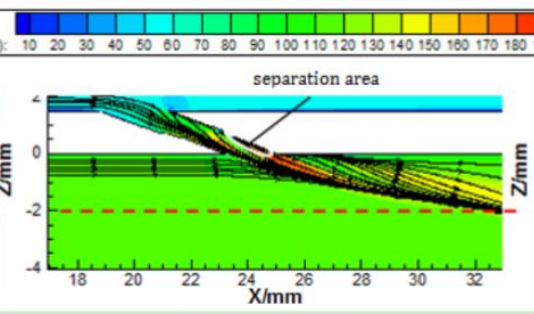

(b) Model 2

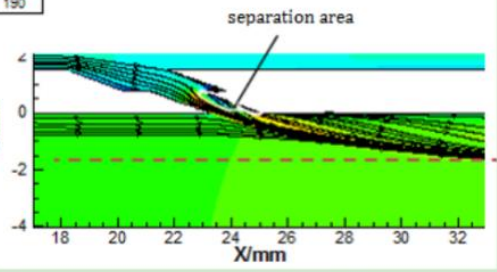

(c) Model 3

Figure 6. Velocity and streamline distribution through hole central plane of three models

In order to further observe the flow of coolant jet downstream, choosing the cross sections of $\mathrm{x}=26, \quad \mathrm{x}=28$ and $\mathrm{x}=30$ (shown by black solid line in

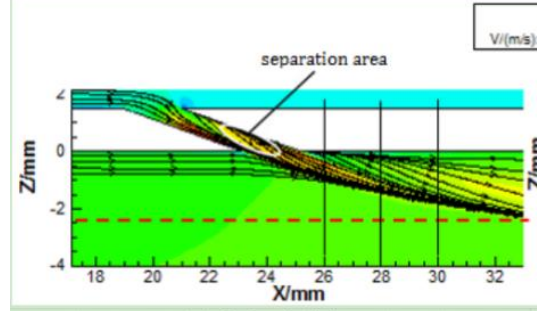

(a) Model 1

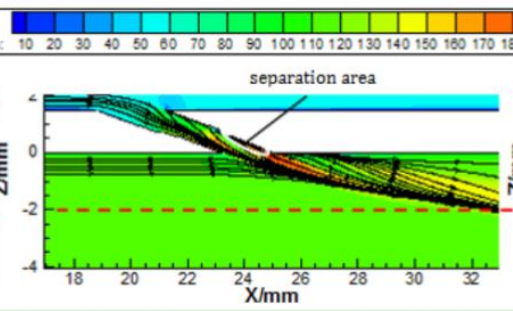

(b) Model 2

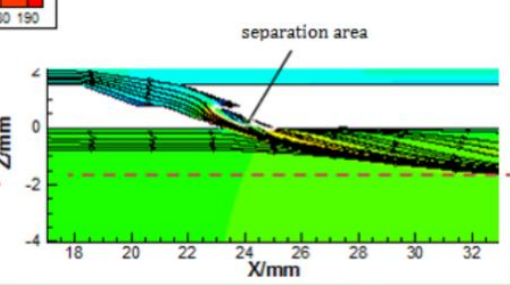

(c) Model 3

Figure ) and named as section I, II and III, respectively, which is convenient for the next analysis and discussion.

\subsection{Vortex distribution in Sections I, II and III of different models}

Figure -9 present the vorticity distribution of three models in section I, II and III. In section I (Figure 7), the vorticity of the stepped hole decreases in the height direction, and with the increase of the stepped hole area ratio (d1/d2), the vorticity distribution remain similar, while the amplitude increases. The increasing of CVP enhances the convective heat transfer between coolant and walls inside holes, and reduces the coolant velocity downwards, causes good adherence of coolant to wall.

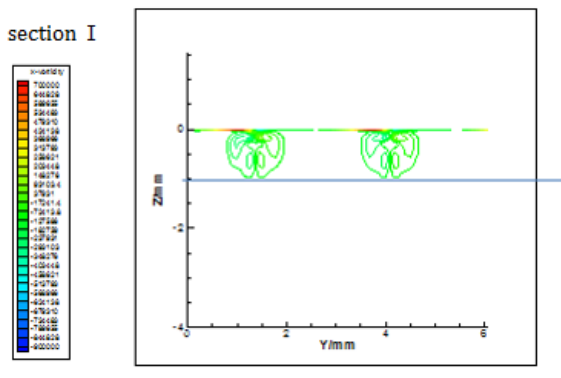

(a)Model 1

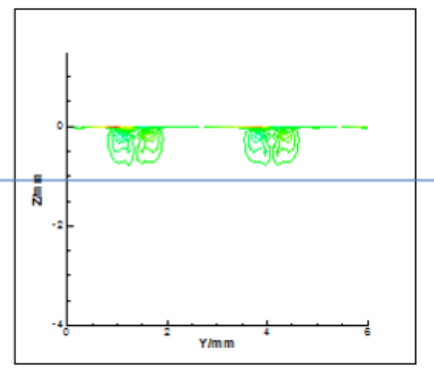

(b)Model 2

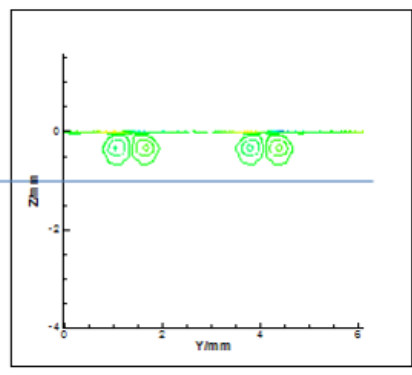

(c)Model 3

Figure 7. Vorticity of three models in section I 


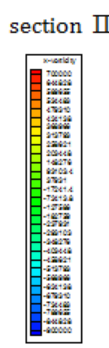

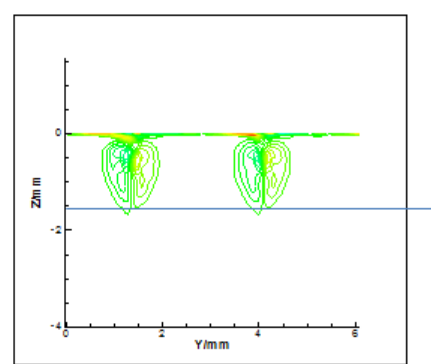

(a)Model 1

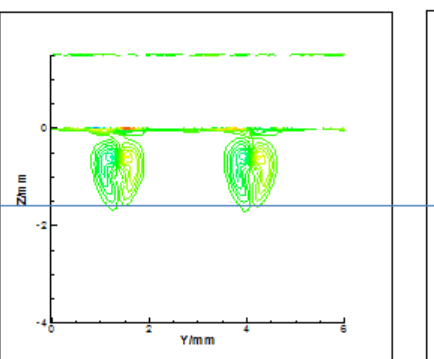

(b)Model 2

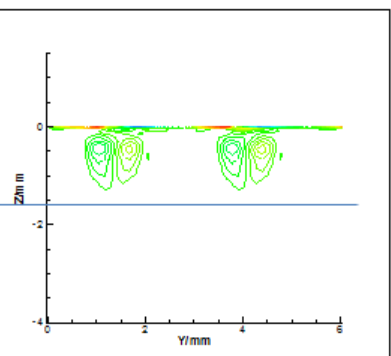

(c)Model 3

Figure 8. Vorticity of three models in section II

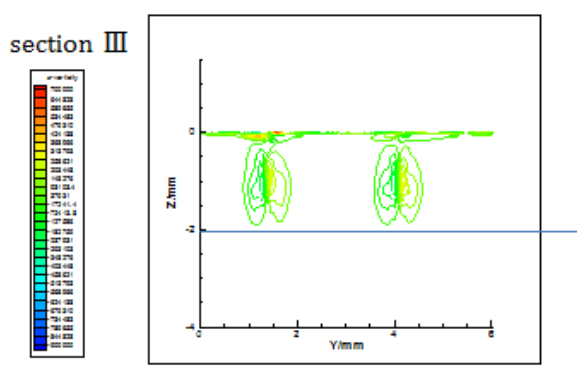

(a)Model 1

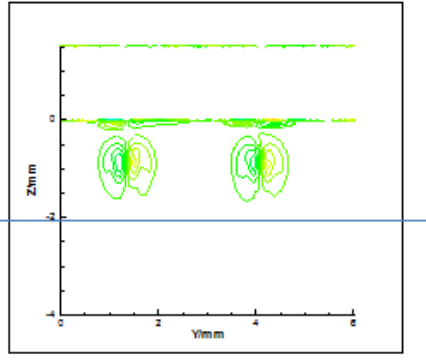

(b)Model 2

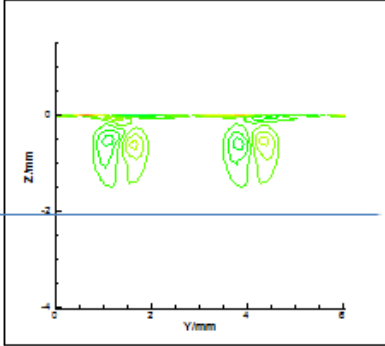

(c)Model 3

Figure 9. Vorticity of three models in section III

With the development of the flow at downstream, the vortex influences larger region in section II and section III in the three models ( shown in Figure andFigure ), which indicates that the influence field of CVP grows larger, and the mixing of coolant flow and mainstream increase in all directions. Taking Model 1 as example, the height of vortex in $\mathrm{Z}$ direction grows from $-1 \mathrm{~mm}$ in section I to $-1.5 \mathrm{~mm}$ in section II and even $-2 \mathrm{~mm}$ in section III. Which indicates that the coolant flow continuously entrains the mainstream in downstream region, for the CVP gradually increase and the vorticity in height direction increases [13-15].

The vorticity in section II and section III of three models are similar, as in section I. It can be concluded that the vorticity of Model 3,Model 2 and Model1 increase gradually in the same cross section, indicating mixing inside holes are enhanced with the area ratio. Further, in downstream, the mixing of coolant and mainstream decreases, and the diffusion in height direction is weak too, which favors the cooling film adherence to the wall, which is consistent with the streamlines in

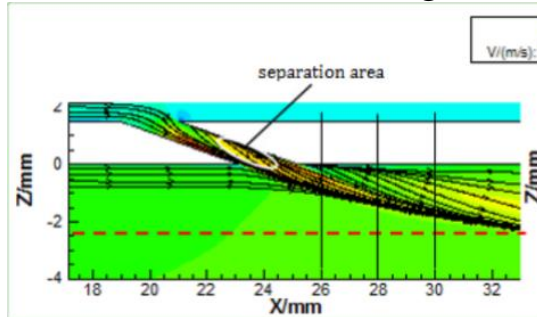

(a) Model 1

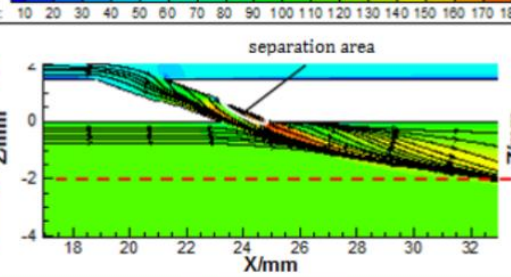

(b) Model 2

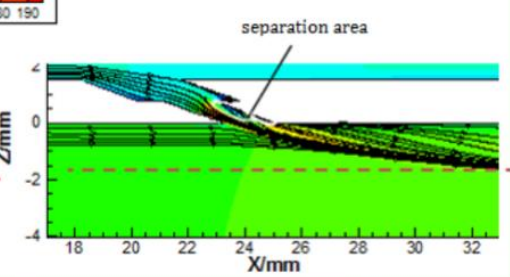

(c) Model 3

Figure .

\section{4. $Y$ component in Velocity Distribution in Different Sections}

Figure shows component of velocity in Y direction in sections I, II and III of three models. Overall, the velocity components of three models reduce gradually from position I to III. Take model 
1 as example, the coolant flows continuously mixes with the mainstream as it goes downstream, results in a gradual decrease in the momentum and velocity. At position I, the component in $\mathrm{Y}$ direction of velocities of the three models are about $6 \mathrm{~m} / \mathrm{s}$. When the flow comes to the II cross section, strongly mixing and momentum exchange occur in span wise direction because of the formation of the CVP, so at position II and III, component of velocity in $\mathrm{Z}$ direction decreases lower than $3 \mathrm{~m} / \mathrm{s}$ and $1 \mathrm{~m} / \mathrm{s}$, respectively. The diffusion of film in lateral direction decreases along $X$ direction, causing by the mixing between coolant and mainstream. The distributions of different models are similar, and the velocity components decreases with the increase of the area ratio. However, the effected region in $\mathrm{Z}$ direction is almost the same in different models [11,12, .

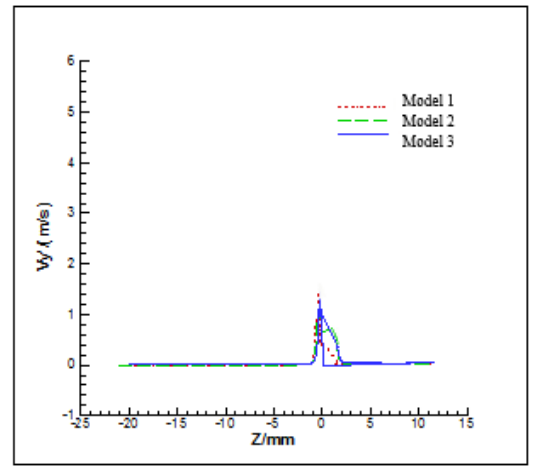

(a)position I

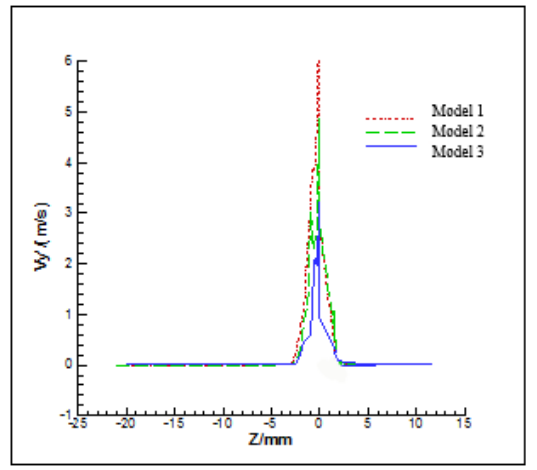

(b)position II

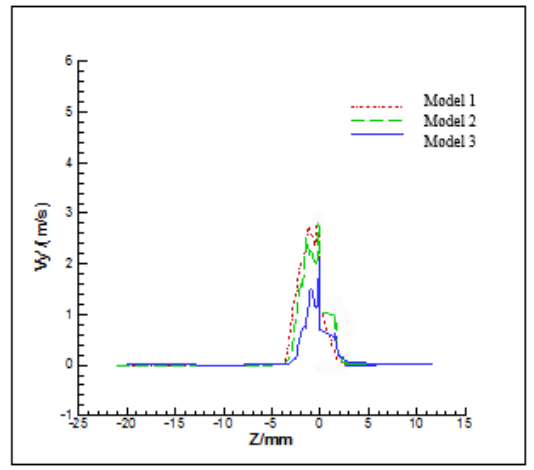

(c)position III

Figure 10. The mean velocity in the $\mathrm{z}$ direction in the cross section at positions I, II and III

Figure shows component of velocity in Z direction in sections I, II and III of three models. At position I near the film hole outlet, the small velocity in $\mathrm{z}$ direction(caused by the small inclined angle) do not induce strongly mixing with the mainstream. As the coolant flow flows downstream, the momentum and the component of velocity in $\mathrm{Z}$ direction both decrease. In the same position, the enhanced impingement reduces the coolant flow velocity as area ratio increases.

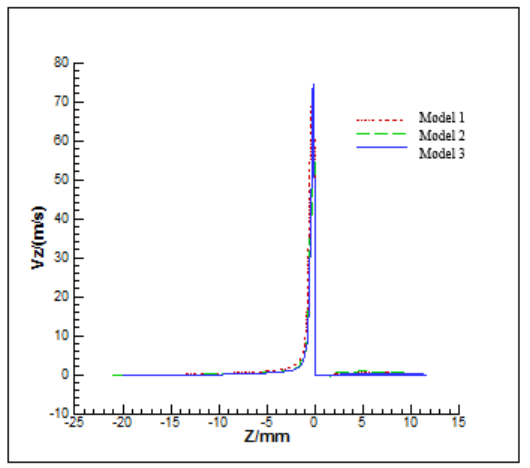

(a) position I

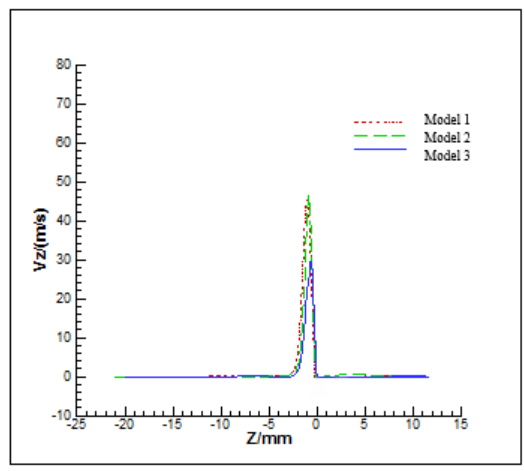

(b) position II

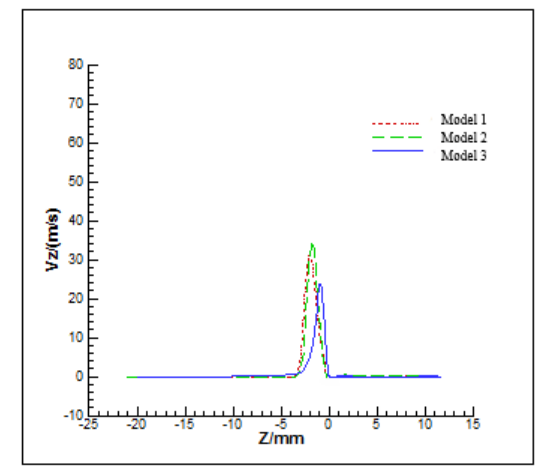

(c) position III

Figure 3. The fluctuating velocity in the y direction in the cross section at positions I, II and III

\section{Conclusions}

The flow and heat transfer characteristics of inclined stepped holes with different area ratio are numerically investigated using the large eddy simulation method, which are compared with 
cylindrical hole model. The main conclusions are as following:

(1) Compared with the cylindrical hole, the flow velocity of the coolant flow inside the stepped film holes decreases after impinging on the stepped plane. As area ratio increases, the impinging is enhanced, while coolant flow velocity decreases further.

(2) The strong CVP structure forms when flow field fully develops. The coolant flow results strongly momentum and heat exchanging with the mainstream in upstream, leads an greatly heat transfer in flow field downstream. The intensity of the CVP decreases, the component in radius direction of velocity decreases, and the cooling film adheres to the wall better.

Acknowledgements: This paper is supported by National Science and Technology Major Project (2017-III-0011-0037).

\section{References}

1. KAMOTANI, Y., GREBER, I., Experiments on a Turbulent Jet in a Cross Flow. Aiaa. J., 32(5), 1972,1451-1460.

2. KRUSE, H., Effects of Hole Geometry, Wall Curvature and Pressure Gradient on Film Cooling Dowmtream of a Single Row. AGARD. Conference. Proceedings., 390, 1985.

3. HAIBIN, L. ZHENLING, L., Recycling utilization patterns of coal mining waste in China. Resour. Conserv. Recycle., 54(12), 2010, 1331-1340.

4. WANG, H., WANG, J., LU, H., BO, G., ZHANG, X., CAO, Y., LIU, L., ZHANG, J., ZHANG, W. Analysis of coating electrode characteristics in the process of removing pollutants from wastewater. Fresenius. Environ. Bull., 29(2), (2020), 715-721.

5. CHENG, Y., SONG, Z., JIN, J., WANG, J., WANG, T., Experimental study on stress wave attenuation and energy dissipation of sandstone under full deformation condition. Arab. J. Geosci., 12(23), 2019, 736-749.

6. CHEN, H., FAN, D., HUANG, J., HUANG, W., ZHANG, G., HUANG, L., Finite Element Analysis Model on Ultrasonic Phased Array Technique for Material Defect Time of Flight Diffraction Detection. Sci. Adv. Mater., 12(5), 2020, 665-675.

7. ZENG, L., CHEN, G., CHEN, H., Comparative Study on Flow-Accelerated Corrosion and Erosion-Corrosion at a $90^{\circ}$ Carbon Steel Bend. Materials, 13(7), 2020, 1780-1795.

8. LIU, Z., FENG, J., WANG, J., Effects of the sharing economy on sequential innovation products. Complexity, 2019, 1-18.

9. ZENG, H. B., LIU, X. G., WANG, W., A generalized free-matrix-based integral inequality for stability analysis of time-varying delay systems. App. Math. Comput., 354, 2019, 1-8.

10. GUO, J., PAN, J., GUO, J., GU, F., KUUSISTO, J., Measurement framework for assessing disruptive innovations. Technol. Forecast. Soc. Change., 139, 2019, 250-265.

11. FRIC, T. F., ROSHKO, A., Structure in the Near Field of the Transverse Jet. in: Proceedings of 7th Symp. on Turbulent Shear Flows, Stanford University, USA, Aug., 1989, 641-646.

12. FRIC, T. F., ROSHKO, A., Vortical Structure in the Wake of a Transverse Jet. Fluid. Mech., 279, 1994, 41-47.

13. KELSO, R. M., DELO, C., SMITS, A. J., Unsteady Wake Structures in Transverse Jets. AGARD Meeting on Computational and Experimental Assessment of Jets in cross flow: April, 1993.

14. ANDREOPOULOS, J., On the Structure of Jets in a Cross Flow. Fluid. Mech., 157, 1985, 163-197.

15. SARKAR, S., BABU, H., Large Eddy Simulation on the Interactions of Wake and Film-Cooling 
Near a Leading Edge. Journal of Turbomach., 137(1), 2014, 011005-1--011005-11.

16. TYAGI, M., ACHARYA, S., Large Eddy Simulation of Film Cooling Flow from an Inclined Cylindrical Jet. ASME. J. Turbomach., 125, 2003, 734-742.

17. EL-GABRY, L. A., THURMAN, D. R., POINSATTE, P. E., HEIDMANN, J. D., Turbulence and Heat Transfer Measurements in an Inclined Large Scale Film Cooling Array: PartI-Velocity and Turbulence Measurements. ASME Paper No., 2011, 541-550.

18. BIDAN, G., VÉZIER, C., NIKITOPOULOS, D. E., Study of Unforced and Modulated Film-Cooling Jets Using Proper Orthogonal Decomposition-Part I: Unforced Jets. J. Turbomach., 135(2), 2012, 021037-1-021037-11.

19. BIDAN, G., VÉZIER, C., NIKITOPOUlOS, D. E., Study of Unforced and Modulated Film-Cooling Jets Using Proper Orthogonal Decomposition-Part II: Forced Jets. J. Turbomach., 135(2), 2013, 021038-1-021038-14.

20. KALGHATGI, P., ACHARYA, S., Modal Analysis of Inclined Film Cooling Jet Flow. $J$. Turbomach., 136(8), 2014, 081007-1--081007-11.

21. SAKAI, E., TAKAHASHI, T., Numerical Study on Effects of Density Ratio on Film Cooling Flow Structure and Film Cooling Effectiveness. Amer. Soci. Mech. Engin. Digit. Collec., 2017, 1-9.

22. WANG, C., ZHANG, J., FENG, H., HUANG, Y., Large eddy simulation of film cooling flow from a fanshaped hole. Appl. Therm. Eng., 129, 2018, 855-870.

23. ZHANG, B., LIN, L., Zhang, N., Xue, S., Ji, H., Experimental Investigation of Geometrical Effect on Flow and Heat Transfer Performance of Lamilloy Cooling Structure. Therm Sci., 24(3A), 2020,1835-1843.

24. LIU, Y. X., YANG, C. N., SUN, Q. D., WU, S. Y., LIN, S. S., CHOU, Y. S., Enhanced embedding capacity for the SMSD-based data-hiding method. Signal Processing: Image Communication, 78, 2019, 216-222.

25. QUAN, Q., HAO, Z., XIFENG, H., JINGCHUN, L., Research on water temperature prediction based on improved support vector regression. Neur. Comput. App., 2020, 1-10.

26. WANG, H., ZHONG, H., BO, G., Existing forms and changes of nitrogen inside of horizontal subsurface constructed wetlands. Environ. Sci. Poll. Res., 25(1), 2018, 771-781.

27. WANG, H., AN, X., ZHANG, Z., Effect of advanced treatment on ammonia nitrogen contained in secondary effluent from wastewater treatment plant. Fresenius. Environ. Bull., 27(4), 2018, 2043-2050.

28. LIU, Z., FENG, J., LIU, B., Pricing and service level decisions under a sharing product and consumers' variety-seeking behavior. Sustainability, 11(24), 2019, 6951.

29. WANG, M., ZHANG, D., CHENG, Y., TAN, S. K., Assessing performance of porous pavements and bioretention cells for stormwater management in response to probable climatic changes. $J$. Environ. Manage., 243, 2019, 157-167.

30. LIU, Z., FENG, J., WANG, J., Resource-Constrained Innovation Method for Sustainability: Application of Morphological Analysis and TRIZ Inventive Principles. Sustainability, 12(3), 2020, 917-939.

31. GU, F., GUO, J., ZHANG, W., SUMMERS, P. A., HALL, P., From waste plastics to industrial raw materials: A life cycle assessment of mechanical plastic recycling practice based on a real-world case study. Sci. Total. Environ., 601, 2017, 1192-1207.

32. GU, F., GUO, J., YAO, X., SUMMERS, P. A., WIDIJATMOKO, S. D., HALL, P., An investigation of the current status of recycling spent lithium-ion batteries from consumer electronics in China. J. Clean. Prod., 161, 2017, 765-780. 
33. ZENG, H. B., LIU, X. G., WANG, W., XIAO, S. P., New results on stability analysis of systems with time-varying delays using a generalized free-matrix-based inequality. J. Franklin. Inst., 356(13), 2019, 7312-7321.

34. ZENG, H. B., TEO, K. L., HE, Y., WANG, W., Sampled-data-based dissipative control of TS fuzzy systems. App. Math. Model., 65, 2019, 415-427.

35. TIAN, X., SONG, Z., WANG, B., ZHOU, G., (2020). A Theoretical Calculation Method of Influence Radius of Settlement Based on the Slices Method in Tunnel Construction. Math. Problem. Eng., 2020.

36. TIAN, X., SONG, Z., WANG, J., Study on the propagation law of tunnel blasting vibration in stratum and blasting vibration reduction technology. Soil. Dynamic. Earth. Eng., 126, 2019, 105813. 37. YANG, L., CHEN, H., Fault diagnosis of gearbox based on RBF-PF and particle swarm optimization wavelet neural network. Neur. Comput. App., 31(9), 2019, 4463,-4478.

38. CAO, Y., LI, Y., ZHANG, G., JERMSITTIPARSERT, K., NASSERI, M., An efficient terminal voltage control for PEMFC based on an improved version of whale optimization algorithm. Energy Reports, 6, 2020, 530-542.

39. CAO, Y., WANG, Q., CHENG, W., NOJAVAN, S., JERMSITTIPARSERT, K., Risk-constrained optimal operation of fuel cell/photovoltaic/battery/grid hybrid energy system using downside risk constraints method. Int. J. Hydrogen Energy., 2020,

40. CAO, Y., WANG, Q., FAN, Q., NOJAVAN, S., JERMSITTIPARSERT, K., Risk-constrained stochastic power procurement of storage-based large electricity consumer. J. Energ. Stor., 28, 2020, 101183.

41. LEI, Z., YANG, J., HUIBIN, H., CHAO, Y., MIN, L., LINTIAN, M., Preparation of soybean oil factory sludge catalyst by plasma and the kinetics of selective catalytic oxidation denitrification reaction. J. clean. Prod., 217, 2019, 317-323.

42. LEI, Z., JIHAO, C., ZHANG, L., HUIBIN, H., YUSU, W., YONGHUI, L., Preparation of soybean oil factory sludge catalyst and its application in selective catalytic oxidation denitration process. J. clean. Prod., 225, 2019, 220-226.

43. CAO, L., TU, C., HU, P., LIU, S., Influence of solid particle erosion (SPE) on safety and economy of steam turbines. Appl. Therm. Eng., 150, 2019, 552-563.

44. WANG, Y., CAO, L., HU, P., LI, B., LI, Y., Model establishment and performance evaluation of a modified regenerative system for a $660 \mathrm{mw}$ supercritical unit running at the IPT-setting mode. Energy, 179, 2019, 890-915.

45. WANG, G., WANG, F., SHEN, F., JIANG, T., CHEN, Z., HU, P., Experimental and optical performances of a solar CPV device using a linear Fresnel reflector concentrator. Renewable Energy, 146, 2020, 2351-2361.

46. LEI, Z., GAO, H., CHANG, X., ZHANG, L., WEN, X., WANG, Y., An application of green surfactant synergistically metal supported cordierite catalyst in denitration of Selective Catalytic Oxidation. J. Clean. Prod., 249, 2020, 119307.

47. WANG, P., LI, J. B., BAI, F. W., LIU, D. Y., XU, C., ZHAO, L., WANG, Z. F., Experimental and theoretical evaluation on the thermal performance of a windowed volumetric solar receiver. Energy, 119, 2017, 652-661.

48. ZHANG, T., WU, X., SHAHEEN, S. M., ZHAO, Q., LIU, X., RINKLEBE, J., REN, H., Ammonium nitrogen recovery from digestate by hydrothermal pretreatment followed by activated hydrochar sorption. Chem. Eng. J., 379, 2020, 122254.

49. GU, F., MA, B., GUO, J., SUMMERS, P. A., HALL, P., Internet of things and Big Data as 
potential solutions to the problems in waste electrical and electronic equipment management: An exploratory study. Waste. Manage., 68, 2017, 434-448.

50. CHEN, X., XU, Y., MENG, L., CHEN, X., YUAN, L., CAI, Q., SHI, W., HUANG, G., Non-parametric partial least squares-discriminant analysis model based on sum of ranking difference algorithm for tea grade identification using electronic tongue data identify tea grade using e-tongue data. Sens. Actuators. B. Chem., 2020, 127924.

51. CHEN, H., HUANG, L., YANG, L., CHEN, Y., HUANG, J., Model-based method with nonlinear ultrasonic system identification for mechanical structural health assessment. Trans. Emerge. Telecommun. Technol., 2020.

52. LIU, Y. X., YANG, C. N., WU, C. M., SUN, Q. D., BI, W., Threshold changeable secret image sharing scheme based on interpolation polynomial. Multi. Tool. App., 78(13), 2019, 18653-18667.

53. HE, Y. B., XIONG, W. H., CHEN, H. X., CAO, C. H., HUANG, W., YANG, L., ZENG, L., DAI, Q. S., CHEN, Y. C., Image quality enhanced recognition of laser cavity based on improved random hough transform. J. Vis. Commun. Image Represent., 2019, 102679.

54. LIU, Y., ZHAO, Q., E-voting scheme using secret sharing and K-anonymity. World. Wide. Web., 22(4), 2019, 1657-1667.

55. ZHU, B., MA, S., XIE, R., CHEVALLIER, J., WEI, Y. M., Hilbert spectra and empirical mode decomposition: A multiscale event analysis method to detect the impact of economic crises on the European carbon market. Comput. Econ., 52(1), 2018, 105-121.

56. YU, D., ZHU, H., HAN, W., HOLBURN, D., Dynamic multi agent-based management and load frequency control of PV/Fuel cell/wind turbine/CHP in autonomous microgrid system. Energy, 173, 2019, 554-568.

$\overline{\text { Manuscript received: } 13.03 .2020}$ 